\title{
O GHEMAT BRASIL E A PESQUISA COLETIVA EM HISTÓRIA DA EDUCAÇÃO MATEMÁTICA
}

\author{
The GHEMAT Brasil and the collective research in history \\ of mathematics education
}

\section{El GHEMAT Brasil y la investigación colectiva en historia de la educación matemática}

\author{
Wagner Rodrigues Valente ${ }^{\alpha *}$
}

Fecha de recepción: 21/04/2019 • Fecha de aceptación: 07/06/2019

Resumo. O presente texto descreve e problematiza as atividades de pesquisa de um dos grupos brasileiros que vem desenvolvendo estudos sobre história da educação matemática. De início, descrevem-se as singularidades da constituição, no Brasil, dessa área de estudos, a partir das diferentes vertentes do campo da Educação Matemática. Em seguida, aborda-se a criação da rede de investigadores que congrega mais de vinte universidades do Brasil, presentes em diferentes pontos do país. O GHEMAT Brasil, hoje, constitui uma associação de pesquisadores com personalidade jurídica, desenvolvendo projetos de pesquisa coletivos envolvendo, praticamente, todo o Brasil. O lema dos pesquisadores do Grupo poderia ser sintetizado por: aprender com os historiadores a produzir história, atentando para o conhecimento acumulado pela História da Educação, usando a formação matemática e a prática da docência em matemática como referentes. Na descrição das atividades do GHEMAT Brasil, tem-se um breve histórico do Grupo, suas escolhas temáticas, suas filiações teórico-metodológicas. Na problematização do trabalho realizado pelo Grupo, na atualidade, evidenciam-se os desafios colocados para a pesquisa coletiva em história da educação matemática que se serve de uma infinidade de documentos digitais contidos em repositório, base de dados do Grupo. Em conclusão advoga-se que os estudos do GHEMAT Brasil devam ser inseridos no âmbito das chamadas Humanidades Digitais.

Palavras-chave: GHEMAT; História da educação matemática; Repositório; Humanidades Digitais.

\footnotetext{
a Departamento de Educação, Escola de Filosofia, Letras e Ciências Humanas, Universidade Federal de São Paulo - GHEMAT Brasil, Estrada do Caminho Velho, 333 - Jd. Nova Cidade - Guarulhos, SP - CEP 07252-312. Brasil. ghemat.contato@gmail.com (D) http://orcid.org/0000-0002-2477-6677
} 
Abstract. This paper describes and discusses the research activities of one of the Brazilian groups that has been carrying out studies on the history of mathematics education. First, we describe the singularities of the constitution of this area of study in Brazil, along with the different aspects of the field of Mathematical Education. We then focus on the creation of a network of researchers that brings together specialists from more than twenty universities in Brazil, present in different parts of the country. Currently, GHEMAT Brasil is an association of researchers with a legal identity, developing collective research projects involving practically the whole of Brazil. The Group's research motto could be summarized as: learning from historians to produce history, paying attention to the knowledge accumulated by the History of Education, using mathematical formation and mathematics teaching practices as references. In the description of GHEMAT Brasil's activities, we present a brief history of the Group, its thematic choices and its theoretical and methodological affiliations. In the problematization of the work carried out by the Group at present, we identify the challenges facing collective research in the history of mathematics education, for which, we use a multitude of digital documents contained in the repository, the Group's database. In conclusion, we argue that GHEMAT Brazil studies should be included in the so-called Digital Humanities.

Keywords: GHEMAT; History of mathematics education; Repository; Digital Humanities.

Resumen. Este artículo describe y discute las actividades de investigación de uno de los grupos brasileños que ha estado desarrollando estudios sobre la historia de la educación matemática. Al principio, describimos las singularidades de la constitución en Brasil de esta área de estudio, desde los diferentes aspectos del campo de la Educación Matemática. Luego, la creación de una red de investigadores que reúne a más de veinte universidades en Brasil, presentes en diferentes partes del país. GHEMAT Brasil, hoy, es una asociación de investigadores con personalidad jurídica, que desarrolla proyectos de investigación colectiva que involucran prácticamente a todo Brasil. El lema de los investigadores del Grupo podría resumirse como: aprender de los historiadores a producir historia, prestar atención al conocimiento acumulado por la Historia de la Educación, usar la formación matemática y la práctica de la enseñanza de las matemáticas como referentes. En la descripción de las actividades de GHEMAT Brasil, tenemos una breve historia del Grupo, sus elecciones temáticas, sus afiliaciones teóricas y metodológicas. En la problematización del trabajo realizado por el Grupo, en la actualidad, se evidencian los desafíos planteados para la investigación colectiva en la historia de la educación matemática, que utiliza una multitud de documentos digitales contenidos en el repositorio, la base de datos del Grupo. En 
conclusión, se argumenta que los estudios de GHEMAT Brasil deberían incluirse en las llamadas Humanidades Digitales.

Palabras clave: GHEMAT; Historia de la educación matemática; Repositorio; Humanidades Digitales.

\section{CONSIDERAÇÕES INICIAIS}

Desde finais da década de 1980 estabeleceu-se, no Brasil, o campo da Educação Matemática. As referências para esse novo campo de pesquisas e de formação de um novo profissional da docência - o educador matemático — datam da realização do I ENEM — Encontro Nacional de Educação Matemática, em 1987. No ano seguinte, foi constituída a SBEM - Sociedade Brasileira de Educação Matemática. E, desde então, foram criadas revistas especializadas, inúmeros congressos da área e mesmo departamentos de Educação Matemática, no âmbito das universidades, para abrigar o novo campo.

Entre nós, brasileiros, foram sendo sedimentadas as chamadas «tendências da Educação Matemática», vertentes de pesquisa e atuação profissional de educadores congregados sob a rubrica Educação Matemática. Assim, algumas dessas vertentes passaram a ser denominadas: modelagem matemática, resolução de problemas, tecnologias, história da matemática, história da educação matemática, dentre outras.

No que toca à história da educação matemática, ao que parece, algo singular ocorreu. Desde finais do século passado, grupos de pesquisa têm sido constituídos no âmbito da temática da história da educação matemática. E são justamente tais grupos que vêm consolidando essa vertente da Educação Matemática. Eles são responsáveis pela criação de eventos nacionais - o ENAPHEM - Encontro Nacional de História da Educação Matemática; eventos internacionais - o CIHEM - Congresso Ibero-americano de História da Educação Matemática. Há, ainda, revistas como a HISTEMAT - Revista de História da Educação Matemática que fazem circular estudos sobre essa vertente de pesquisa. De outra parte, em várias universidades brasileiras tem sido criada a disciplina "História da Educação Matemática» nos cursos de Licenciatura em Matemática.

Por certo, os modos de funcionamento e organização de cada um dos grupos de pesquisa que deram e dão suporte à história da educação 
matemática no Brasil mostram-se diferentes. Neste texto, apresentamos, em particular, o GHEMAT Brasil.

\section{DO GHEMAT AO GHEMAT BRASIL}

No ano 2000 foi criado o GHEMAT-SP. Àquela altura, apenas GHEMAT, um pequeno grupo que reunia o professor Wagner Rodrigues Valente e seus alunos de mestrado e doutorado em Educação Matemática. Logo ao princípio de sua existência, o Grupo foi contemplado com um projeto de pesquisa, sob financiamento FAPESP - Fundação de Amparo à Pesquisa do Estado de São Paulo, que congregava uma meia dúzia de pesquisadores em torno de uma temática comum: investigar história da educação matemática no ensino secundário a partir da década de 1930, quando ocorre uma revolução política no Brasil. Mestrandos e doutorandos passaram, com isso, todos eles, a voltarem atenção para essa temática, analisando-a sob diferentes subtemas e com o uso de variada documentação para a pesquisa: livros didáticos, legislação escolar, arquivos de escolas, provas e exames etc.

Em tempo relativamente curto, o GHEMAT-SP conquistou junto à CAPES - Coordenação de Aperfeiçoamento de Pessoal de Nível Superior um projeto de cooperação internacional com Portugal. A temática era abrangente: «A matemática nas escolas do Brasil e de Portugal: estudos históricos comparativos». Diferentemente do usual, o projeto de cooperação internacional abriu-se para outras instituições além daquela executora (a Pontifícia Universidade Católica de São Paulo). Comumente tais projetos são realizados no âmbito de uma mesma instituição, envolvendo os seus docentes e pesquisadores. No entanto, várias outras instituições foram convidadas a participarem da pesquisa. $\mathrm{O}$ projeto possibilitou a constituição de uma verdadeira rede de pesquisadores, juntando professores de diferentes universidades brasileiras que, aliados a três instituições de ensino superior portuguesas (Escola Superior de Educação, Universidade de Lisboa e Universidade Nova de Lisboa) levaram adiante o projeto de investigação da matemática moderna nas escolas desses dois países.

A experiência de trabalho coletivo de pesquisa por meio do projeto de cooperação internacional com Portugal foi decisiva para a organização de outros estudos de caráter conjunto promovido pelo GHEMAT-SP. 
O Grupo paulista também, com suas ações, mobilizou demais pesquisadores de outras instituições a criarem seus próprios grupos locais de trabalho nas diferentes universidades brasileiras. Hoje eles existem em mais de vinte estados do país.

Logo vieram, também, editais de fomento à pesquisa que priorizavam grandes redes de pesquisadores, com orçamentos mais vultuosos para o trabalho. Assim, o GHEMAT-SP, congregado com outros grupos de pesquisa, passou a ganhar editais brasileiros de fomento à pesquisa relativamente à história da educação matemática, inserindo-se definitivamente na realização de projetos coletivos.

Na sequência dos trabalhos, outro projeto de caráter internacional foi conquistado: estudos históricos comparativos entre o Brasil e a França relativamente à matemática dos primeiros anos escolares, séculos XIX e XX. Essa nova pesquisa congregou vinte universidades brasileiras e duas francesas: Université de Paris SUD e Université de Limoges. Nessa altura, o GHEMAT transferiu-se para a Universidade Federal de São Paulo, onde a coordenação do Grupo passou a lecionar.

O GHEMAT desde o início de suas atividades promoveu seminários temáticos de modo a concentrar em dada época do ano, todos os seus pesquisadores, de modo que fosse possível apresentar e debater resultados de pesquisa de projetos coletivos em andamento. Esses seminários já se encontram em sua $17^{a}$ edição. O último deles pode ser consultado no endereço http://xviiseminariotematico.paginas.ufsc.br/

Algo muito importante para o Grupo ocorreu em meio à realização do Seminário Temático realizado na Universidade Federal de Roraima: os pesquisadores decidiram institucionalizar uma prática de pesquisa que já vinha ocorrendo, em termos da rede de pesquisadores já existente. Foi criado, em abril de 2018, o GHEMAT Brasil - Grupo Associado de Estudos e Pesquisas sobre História da Educação Matemática. Com ele, eleita a primeira diretoria, busca-se uma organização ainda mais sistematizada do trabalho do Grupo.

Nos termos do Estatuto do GHEMAT Brasil, trata-se de:

Art. 4․ O GHEMAT Brasil, através dos seus estudos e pesquisas, tem por fim prestar serviços sociais, educacionais e culturais, de subsidiar tecnicamente agências afins. 
Art. 5․ Para a consecução de seus fins, o GHEMAT Brasil tem, entre outros objetivos:

I-promover levantamentos, estudos e pesquisas com vistas a divulgar dados, reflexões e informações referentes à História da Educação Matemática;

II-elaborar e executar programas de capacitação de recursos humanos;

III-prestar serviços de consultoria acadêmica e afins;

IV-elaborar e divulgar pesquisas no campo da História da Educação Matemática;

V-promover seminários, simpósios, congressos e eventos congêneres sobre História da Educação Matemática;

VI-editar, divulgar e permutar publicações sobre História da Educação Matemática;

VII-estabelecer convênios e intercâmbio com outras entidades congêneres e/ou semelhantes.

A institucionalização do GHEMAT Brasil aponta para um trajeto ainda mais profissional da pesquisa. O Grupo, de caráter nacional, passará a ter possibilidade de concorrer a editais de pesquisa nacionais e internacionais, e realizar atividades a partir dos resultados dessas investigações, de modo a manter uma autonomia relativa das universidades. Em boa medida, as universidades brasileiras têm voltado a sua atenção para os cursos de graduação. E há mesmo muitas delas que não contabilizam as horas de pesquisa dos professores na composição de sua jornada de trabalho. O fato é lamentável e coloca as atividades dos pesquisadores como marginais em sua atuação universitária.

\section{SOBRE AS TEMÁTICAS DE PESQUISAS DO GHEMAT}

À medida em que, no Brasil, vários grupos de pesquisa passaram a se dedicar e mesmo a se constituírem como grupos de história da educação matemática, houve necessidade de melhor caracterização de cada um deles. E essa caracterização, sobretudo, foi dada pelos pressupostos de 
trabalho de cada um desses coletivos. Um deles refere-se à relação dos grupos outros campos disciplinares; outro aspecto importante diz respeito a como tratam a história da educação matemática relativamente ao campo da Educação Matemática.

Desde o início, o GHEMAT reafirmou a sua proximidade com os estudos de História da Educação. Assim, o trabalho a ser realizado sempre circunscreveu a história da educação matemática como uma especialidade da História da Educação, que por sua vez, constitui-se num ramo da História. O lema dos pesquisadores do GHEMAT Brasil poderia ser sintetizado por: aprender com os historiadores a produzir história, atentando para o conhecimento acumulado pela História da Educação, usando a formação matemática e a prática da docência em matemática como referentes.

No período compreendido entre o ano 2000 até 2008 as temáticas de pesquisa do GHEMAT privilegiaram o que outrora, no Brasil, era denominado ensino secundário. Em boa medida, os estudos realizados por alunos de iniciação científica, por mestrandos e doutorandos ativeram-se a análises sobre a disciplina escolar matemática. Como, ao longo do tempo, foi sendo constituída a matemática escolar enquanto disciplina para ensino no curso secundário? Essa questão orientou a realização de estudos que percorreram desde as primeiras décadas do século XVIII até as décadas finais do século XX. ${ }^{1}$ Em termos das referências teórico-metodológicas utilizadas os estudos alicerçaram-se em trabalhos de André Chervel (disciplina escolar), de Dominique Julia (cultura escolar), de Roger Chartier (História Cultural) dentre outros autores.

A partir de 2009, o Grupo voltou a sua atenção prioritariamente para a matemática presente nos primeiros anos escolares em perspectiva histórica. Por meio do projeto coletivo apoiado pelo CNPq - Conselho Nacional de Desenvolvimento Científico e Tecnológico, um amplo programa de investigações passou a ser realizado pelo GHEMAT. A proposta intitulada «A constituição dos saberes elementares matemáticos: a Aritmética, a Geometria e o Desenho no curso primário em perspectiva histórico-comparativa, 1890-1970» mobilizou dezenas de pesquisadores em mais de vinte estados brasileiros.

${ }^{1}$ Leia-se, como exemplo, a obra: Wagner Rodrigues Valente, Uma história da matemática escolar no Brasil, 1730-1930 (São Paulo:Annablume, 2007). 
No Brasil, em grande medida, a trajetória do ensino primário fez-se localmente, sob a égide de governos estaduais e municipais, algo diferente do ensino secundário que sempre teve caráter centralizado, tendo por referência um liceu modelo: o Colégio Pedro II, no Rio de Janeiro, fundado em 1837. Assim, a temática de estudo que envolvia a matemática nos primeiros anos escolares, mais e mais necessitou do concurso vários investigadores a estudar realidades locais, de modo que fosse possível avançar no entendimento das transformações da matemática no curso primário no Brasil. ${ }^{2}$

Como continuidade dos projetos anteriores que analisaram a constituição dos saberes escolares em termos das transformações da matemática enquanto disciplina, para o curso secundário; e como matéria, para o primário, o Grupo em seus mais recentes projetos coletivos voltou a atenção para a formação de professores em perspectiva histórica. Tal interesse pareceu constituir algo um tanto natural considerando as análises que os historiadores da educação vêm fazendo relativamente ao papel dos professores na constituição dos saberes escolares, das disciplinas ou matérias de ensino. Nesse sentido, diz-nos Ossenbach que

Tendo em conta o papel fundamental que os professores jogam na criação das disciplinas escolares, cabe entende-las como um campo de poder social ou acadêmico [...]. Os grupos de professores de uma determinada disciplina se apropriam de espaços sociais e acadêmicos, determinam conteúdos e orientação pedagógica de cada campo disciplinar; estabelecem requisitos para a competência do ensino da disciplina (formação, titulação, mecanismos de seleção ou acesso) [...] (tradução nossa). ${ }^{3}$

Para além disso, a mesma autora, na análise dos estudos de Antonio Viñao, pondera que quando analisamos disciplinas escolares como

\footnotetext{
2 Citem-se como alguns resultados do projeto a publicação de obras como: David A. Costa e Wagner Valente (orgs.), Saberes matemáticos no curso primário: o que, como e por que ensinar? (São Paulo: LF Editora, 2014), Neuza B. Pinto e Wagner R. Valente (orgs.), Saberes elementares matemáticos em circulação no Brasil: dos documentos oficiais às revistas pedagógicas, 1890-1970. (São Paulo: L F Editorial, 2016), e Iran A. Mendes e Wagner R. Valente (orgs.), A Matemática dos manuais escolares: curso primário, 1890-1970 (São Paulo: Editora Livraria da Física, 2017).

3 Gabriela Ossenbach-Sauter, «Historia de las disciplinas y manualística escolar», en Educación, Historia y Sociedad - El legado historiográfico de Antonio Viñao, ed. Pedro Luis Moreno (Valencia: Tirant Humanidades, 2018), 133-166. (cita em 144).
} 
campos acadêmicos e seu controle exercido por um grupo determinado de professores, deveremos, necessariamente, «estudar a história das disciplinas escolares em estreita relação com os processos de profissionalização docente» ${ }^{4}$.

Desse modo, a análise das transformações das disciplinas escolares ou das matérias de ensino, necessita um estudo que possa articular esses saberes escolares com aqueles ministrados na formação de professores ao longo do tempo. Será essa articulação dos saberes — de um lado aqueles postos no ensino; de outro, os da formação de professores que integrarão o saber profissional do professor.

O estudo do saber profissional da docência e, em particular, da docência da matemática tem em conta o processo histórico de sua constituição. Ofícios produzem conhecimentos. Esses conhecimentos são elaborados por meio das experiências dos sujeitos em ação, realizando suas práticas de trabalho: professores que ensinam matemática realizando suas atividades didático-pedagógicas no cotidiano de suas aulas. Ao longo do tempo, por meio de processos e dinâmicas complexos, parte desses conhecimentos são passíveis de sistematização, transformando-se em saber. O saber elaborado ganha poder de circulação e apropriação para além dos lugares, contextos e experiências que possibilitaram aos sujeitos (professores) a produção de conhecimentos. Tem-se, desse modo, para uma dada época, a produção do saber profissional. Assim, é possível, em síntese, ponderar que os estudos históricos sobre o tema da matemática a fazer parte da formação do professor poderão evidenciar como vêm sendo elaborados os saberes profissionais da docência em matemática.

A revelação de processos e dinâmicas que caracterizam o saber profissional mostrar-se-á fundamental para propostas presentes e futuras de formação de professores e, em particular, de professores que ensinam matemática. O tratamento do tema da elaboração histórica do saber profissional do professor aponta para estudos de longa duração, com a mobilização de milhares de documentos de diversas naturezas. E, no caso das pesquisas do GHEMAT Brasil, do saber profissional do professor que ensina matemática. Essa justamente é a temática de projeto amplo, que está em desenvolvimento pelo Grupo: «A matemática no ensino

\footnotetext{
4 Ossenbach-Sauter, «Historia de las disciplinas y manualística escolar», 145.
} 
e na formação de professores: processos e dinâmicas de produção de um saber profissional, 1890-1990», com o apoio da FAPESP, projeto temático, com período de cinco anos para a sua realização. Junto a esse projeto, outra pesquisa articulada à investigação do saber profissional, voltará a atenção para os professores como experts, analisando ao longo de cem anos, como ocorreram as mudanças no saber profissional do professor que ensina matemática: «Os experts e sistematização da matemática para o ensino e para a formação de professores, 1890-1990», com o apoio do $\mathrm{CNPq}$, projeto Edital Universal Faixa C, com duração de três anos para a sua realização.

\section{O CENTRO DE DOCUMENTAÇÃO DO GHEMAT-SP E O REPOSITÓRIO DE CONTEÚDO DIGITAL}

Como já se disse anteriormente, o GHEMAT Brasil caracteriza-se pela reunião de dezenas de pesquisadores em torno de projetos coletivos de pesquisa no âmbito da história da educação matemática. A dimensão coletiva se faz presente inicialmente pelo interesse comum dos pesquisadores em analisar uma dada temática. Outras dimensões importantes devem ser destacadas nesse trabalho e que viabilizam a realização dos projetos coletivos. Uma delas é existência de um Centro de Documentação do Grupo. Destaque-se, de início, que, localmente, cada grupo de pesquisa componente do GHEMAT Brasil tem seus espaços, seus arquivos, seus materiais de pesquisa. De outra parte, foi possível, desde da criação do GHEMAT-SP, no ano 2000, reunir acervos documentais físicos, de modo a constituir um Centro de Documentação. No Centro encontra-se um conjunto grande de obras didáticas de matemática. Mas, sobretudo, o local abriga acervos pessoais de vários personagens ícones da Educação Matemática brasileira como Ubiratan D’Ambrosio, Osvaldo Sangiorgi, Euclides Roxo dentre vários outros professores.

Os acervos pessoais de professores constituem material importante para a pesquisa em história da educação matemática. São compostos, em geral, de uma variedade de documentos como cartas, projetos e rascunhos de obras e livros, material elaborado pelo personagem que não ganhou publicação em escala ampla, mas que orientou e constituiu etapa de construção intermediária de propostas para o ensino de matemática e/ou para a formação de professores dentre outros documentos. Destaque-se que esse tipo de material não é considerado importante 
para as bibliotecas, e mesmo para os arquivos públicos; tais lugares mostram-se interessados, normalmente, em acervos de cientistas reconhecidos internacionalmente. Pouco apelo têm os acervos de antigos professores de matemática. No entanto, foi por intermédio dos acervos pessoais do professor Euclides Roxo, por exemplo, que se tornou possível a escrita da história da educação matemática no curso secundário brasileiro do período 1920-1950.

A consulta aos acervos do Centro de Documentação é pública e pode ser agendada antecipadamente ${ }^{5}$.

Uma outra dimensão coletiva do trabalho do GHEMAT Brasil refere-se ao compartilhamento dos documentos para a pesquisa. Ele se dá pelo uso de um Repositório de Conteúdo Digital. Os repositórios são sistemas que armazenam, organizam e possuem sistemas de buscas digitais. Dentro desse contexto se articulam com um conjunto de serviços de curadoria aos objetos digitais tais como a preservação e o uso racional dos metadados. ${ }^{6}$

A preocupação com a digitalização de documentos de modo a preservá-los, a tornar possível a sua circulação em âmbito mais amplo, desde o início, constituiu objetivos do trabalho do Grupo. Cite-se, por exemplo, a digitalização de cerca de três mil provas e exames de matemática do antigo Exame de Admissão - verdadeiro vestibular para acesso ao curso secundário brasileiro («Os exames de admissão do Ginásio: 19311969»). Foram produzidos três CDROM para abrigar essa documentação. O material ganhou grande circulação entre os pesquisadores e até o momento constitui referência para as investigações sobre avaliações escolares.

Outros exemplos ainda podem ser citados, tais como: «A Matemática do colégio: livros didáticos para a história de uma disciplina» (2011). Trata-se de um DVD que possui uma base de dados de livros didáticos destinados ao curso colegial, desde o período da estruturação desse nível escolar (década de 1930) até finais do chamado Movimento da Matemática Moderna (1980). Um outro importante acervo encontra-se disponível em

\footnotetext{
5 Para maiores informações consulte-se o endereço: www.ghemat.com.br

6 Abby Clobridge, Building a Digital Repository Program with limited resources (Oxford: Chandos Publishing, 2010).
} 
outro DVD «IV Congresso Brasileiro do ensino de Matemática Belém do Pará, 22 a 28 de julho de 1962»(2009). Desde 1955 tiveram início os Congressos do Ensino da Matemática no Brasil. Bahia, Rio Grande do Sul, Rio de Janeiro, foram sedes dos primeiros encontros. Para o IV Congresso, Belém do Pará, foi o lugar escolhido. No entanto, diferentemente de outros congressos brasileiros, não foram publicados os Anais do Evento. Este DVD tem por conteúdo a digitalização de parte da documentação amealhada do IV Congresso, e que se encontra fisicamente no Centro de Documentação do GHEMAT - Grupo de Pesquisa de História da Educação Matemática. Tais exemplos ilustram a preocupação e algumas das ações efetivas do Grupo na produção dos acervos visando a disponibilização das fontes para a comunidade acadêmica.

Mas estes exemplos citados possuem limitações. As iniciativas das mídias digitais gravadas, por exemplo, com o uso do DVD, como suporte material, retratam esta limitação: para além da quantidade finita de informação, só terá acesso a elas, aquele que possuir o DVD gravado. Novos tempos surgiram e o Grupo passou a utilizar um repositório de conteúdo digital.

O Repositório constituindo-se como espaço virtual e disponibilizado na rede (internet) torna-se uma importante opção na qual têm sido alocadas as fontes digitalizadas dos projetos coletivos de pesquisa. A utilização do repositório não está em oposição às bases de dados já comentadas neste texto, disponibilizadas em mídias como o DVD, mas de forma mais apropriada para esta finalidade, o Repositório assume como objetivo, por exemplo, a franquia das imagens digitalizadas de fontes primárias. O Repositório pode ser entendido como «uma forma de armazenamento de objetos digitais que tem a capacidade de manter e gerenciar material por longos períodos de tempo e prover o acesso apropriado». ${ }^{7}$ Os repositórios digitais se filiam a uma área na qual se aplicam as tradicionais expertises da biblioteconomia em uma ambiência virtual. Fundamentalmente, o trabalho é semelhante aquele realizado numa biblioteca: catalogar, aspectos da curadoria, disseminação e preservação da informação.

\footnotetext{
7 Cassandra L. Viana, Miguel Ángel Márdero Arelano e Milton Shintaku, «Repositórios institucionais em ciência e tecnologia: uma experiência de customização do DSpace», Instituto Brasileiro de Informação em Ciência e Tecnologia - IBITIC. Disponível em: http://bibliotecas-cruesp.usp.br/ 3sibd/docs/viana358.pdf. Acesso em 15 de dez. 2018.
} 
O Repositório que acolhe as pesquisas do GHEMAT Brasil encontra-se «fisicamente» sediado na Universidade Federal de Santa Catarina, uma das diversas instituições de ensino e pesquisa na qual alguns membros do Grupo se filiam. Baseado na estrutura do DSpace5, com arquitetura simples e eficiente, utiliza-se de tecnologia de ponta e está direcionado ao acesso aberto, intencionalmente criado para esta finalidade. A estrutura do Repositório constitui-se na forma de subunidades naturais e «comunidades» onde cada comunidade tem suas «coleções» que, por sua vez, contém «itens» que representam os conteúdos digitais. Todas estas informações são alimentadas por meta-dados que têm como finalidade facilitar a localização e recuperação das informações. Ou seja, todos os registros podem ser consultados por palavras chave ou qualquer outro sistema de busca mais avançado. ${ }^{8} \mathrm{O}$ Repositório em discussão neste artigo se alinha à sub-comunidade História da Educação Matemática, aninhada ao Centro de Ciências da Educação da UFSC. Trata-se de um repositório virtual, aberto e institucionalizado, especificamente para armazenar fontes diversas, ensaios e pesquisas voltadas para a História da Educação Matemática. Poderá ser consultado a partir de qualquer dispositivo com acesso à internet no seguinte endereço: https://repositorio.ufsc.br/handle/123456789/1769.

\section{O GHEMAT BRASIL E OS DESAFIOS DA PESQUISA EM HISTÓRIA DA EDUCAÇÃO MATEMÁTICA EM TEMPOS DE HUMANIDADES DIGITAIS}

Por Humanidades Digitais entenda-se, aqui, a expressão que designa uma nova era das pesquisas nas ciências humanas ancorada no uso de dados alocados em grandes repositórios de conteúdos digitais. Integrar-se a esse novo modo de fazer pesquisas elaborando documentos digitais e servindo-se deles para o desenvolvimento de projetos de investigação parece ser algo fundamental em tempos de revistas especializadas on-line, de bibliotecas digitais e de um grande número de possibilidades disponíveis para o trato de qualquer tema ligado às humanidades, área pouco afeita à proximidade dos recursos tecnológicos.

\footnotetext{
Ligia Café et al., "Repositórios Institucionais: nova estratégia de publicação científica na rede», Anais. ENDOCOM, Belo Horizonte, MG, 13 (set. 2003).
} 
Em tempo recente, como já mencionado anteriormente, a FAPESP concedeu financiamento inédito para a área da Educação Matemática. Em sua linha de auxílio à pesquisa denominada "projeto temático» foi destinada uma soma considerável para o desenvolvimento da investigação intitulada «A matemática na formação de professores e no ensino: processos e dinâmicas de produção de um saber profissional, 18901990».9 Junto a esse projeto, também como já observado, obteve-se auxílio dado pelo CNPq para a investigação sobre os experts. Ambas a serem conduzidas pelo GHEMAT Brasil.

A elaboração da problemática de pesquisa desses projetos têm como referência a seguinte interrogação: Que matemática deverá formar o futuro professor? Com ela, investiga-se o saber profissional do professor que ensina matemática. Como são produzidos, sistematizados e institucionalizados os saberes profissionais, os saberes profissionais do professor que ensina matemática? Como caracterizar a matemática como um saber profissional da docência?

A hipótese condutora das pesquisas envolvidas nesses projetos é a de que desde finais do século XIX vêm sendo elaborados os saberes profissionais da docência, da docência em matemática. E eles, ao longo do tempo, têm sido sistematizados sob rubricas que, nas últimas décadas do século XX, vão cada vez mais tendo status epistemológico de saber, ultrapassando suas formas iniciais dadas pela pedagogia das matemáticas, pelas metodologias do ensino de matemática e, por último, pela didática das disciplinas (Didática da Matemática), revelando-se como uma matemática para ensinar, articulada à matemática a ensinar.

O banco de dados construído pelo GHEMAT Brasil, para o desenvolvimento dessas pesquisas, dia após dia, vem crescendo em volume de documentos digitalizados. Contam-se, atualmente, quatro mil pastas com documentação de mais de vinte estados brasileiros, reunindo livros didáticos, revistas pedagógicas, provas e exames de alunos e professores, documentos de acervos pessoais, cadernos de alunos e professores dentre outros documentos.

Os desafios colocados para os projetos em andamento, tendo em conta o volume considerável de documentos já digitalizados, levam as pesquisas

\footnotetext{
9 Para maiores informações consulte-se: https://bv.fapesp.br/pt/auxilios/98879/a-matematica-na-formacao-de-professores-e-no-ensino-processos-e-dinamicas-de-producao-de-um-saber-p/
} 
a inscreverem-se nesse novo tempo das Humanidades Digitais. Com isso, novas questões de âmbito metodológico agregam-se à investigação do saber profissional do professor que ensina matemática.

Por certo, o trabalho com milhares de documentos apresenta desafios enormes para a pesquisa. Como tratar essa quantidade de informações? Como, a partir delas, elaborar conhecimento? Como transformar a informação dispersa por entre milhares de documentos digitalizados na produção de um novo saber? Essa última interrogação nos remete ao título de recente obra do historiador Peter Burke. A obra, lançada em 2015, em língua inglesa; em português, em 2016; e, em 2017, em espanhol, tem título autoexplicativo: «O que é a história do saber? Como a informação dispersa se converteu em saber consolidado ao longo da história». ${ }^{10} \mathrm{Nela}$, o historiador pondera que todo saber tem uma história.

Na perspectiva da história do saber, é possível levar em conta que o saber profissional não é um dado que se possa ter a priori. O saber profissional tem uma história. Se há um ofício, uma profissão, ela historicamente constrói os seus saberes. Assim, ao considerarmos o saber profissional da docência há que se ponderar o que historicamente vêm ocorrendo de modo a que haja a construção desse saber. E o quê as pesquisas precisam mostrar é justamente "como a informação dispersa se converteu em saber consolidado» num dado período histórico. No caso que nos interessa, a pergunta poderá ser formulada do seguinte modo: como a informação dispersa se converteu em saber profissional do professor que ensina matemática numa dada época? A leitura desses saberes consolidados nos dias atuais pode ser feita em termos dos saberes que hoje estão presentes na formação inicial dos professores e nas referências curriculares para ensino na Escola Básica. Como chegamos até aqui? Compreender tais processos e dinâmicas possibilitam considerar o saber profissional da docência noutras bases.

Se há uma clareza relativamente às bases conceituais que auxiliam o desenvolvimento da pesquisa e, além disso, vários desafios preliminares importantes foram já vencidos - constituição de uma rede de pesquisadores com interesses comuns, mobilizados em torno de um amplo

\footnotetext{
10 Peter Burke, ¿Qué es la historia del conocimiento? Cómo la información dispersa se ha convertido
} en saber consolidado a lo largo de la historia (Argentina: Siglo Veintiuno Editores, 2017). 
projeto temático e alocação de documentos em ambiente aberto da internet, vindos de diversos estados brasileiros, digitalizados para a pesquisa histórica, de modo a possibilitar acesso aos vários grupos locais - de outro lado, muito há para ser feito em termos de tratamento dos documentos digitalizados para a pesquisa.

Há, efetivamente, uma grande equipe de pesquisadores ao redor de uma base de dados com milhares de documentos, realizando pesquisas em torno de temática comum, qual seja, a de investigar no período de cem anos, como foi sendo elaborado o saber profissional do professor que ensina matemática.

A atual etapa em desenvolvimento vem utilizando a documentação ainda de modo que se poderia dizer "pré-Humanidades Digitais» na medida em que ainda não entrou em funcionamento a mineração dos dados, o tratamento algorítmico das informações contidas nos documentos digitalizados. ${ }^{11}$

Que necessidades estão postas para o desenvolvimento dos projetos em termos do tratamento dos milhares de documentos já digitalizados?

No retorno aos textos dos projetos, tem-se a caracterização da matemática a ensinar, da matemática para ensinar e da matemática ensinada. Assim, explicitar o saber profissional do professor que ensina matemática implica na elaboração teórica dessas matemáticas, tendo em conta que o saber profissional do professor que ensina matemática é dado pela articulação entre a matemática a ensinar e a matemática para ensinar.

Admite-se, por hipótese de pesquisa, que cada tempo histórico, por meio de lutas de hegemonia entre diferentes atores sociais e políticos, estabelece padrões que buscam consensos. Tais consensos, do ponto de vista da escola, intentam sempre mostrarem-se como formas naturais de pensar a educação, a escola, frente às necessidades colocadas para uma dada época. Integram esse discurso que busca o consenso, por meio de lutas de hegemonia, as finalidades atribuídas à escola, a ideias sobre

11 «O processo de minerar dados para descobrir conexões escondidas e prever tendências futuras tem uma longa história. Por vezes chamado de "descoberta de conhecimento em bancos de dados", o termo "mineração" só foi cunhado nos anos 1990, mas sua base compreende três disciplinas científicas entrelaçadas que existem há tempos: estatística (o estudo numérico das relações entre dados), inteligência artificial (inteligência exibida por softwares e/ou máquinas, que se assemelha à humana) e machine learning (algoritmos que podem aprender com dados para realizar previsões)». Referência: https://www.sas.com/pt_br/insights/analytics/mineracao-de-dados.html\#dmhistory 
como deve se dar o ensino e a aprendizagem, o estabelecimento de saberes que devem estar presentes no ensino e na formação de professores, dentre vários outros temas. Em específico, os projetos interessam-se por este último aspecto: aquele relacionado aos saberes a estarem presentes no ensino e na formação de professores que ensinam matemática.

Dessa forma, o desenvolvimento das pesquisas atuais do GHEMAT Brasil atenta para a busca de padrões de saberes para a formação de professores que ensinam matemática, estabelecidos no período compreendido entre 1890 a 1990. Tais padrões resultam de processos de decantação, que ocorrem quando, numa dada época, interagem de um lado as ciências da educação e um dado campo disciplinar com os seus resultados de pesquisa; e, de outro, as interações vindas das práticas pedagógicas escolares. O resultado dessa decantação é, para um dado tempo, o saber profissional do professor.

Analisar um conjunto grande de documentos relativos às normativas oficiais do ensino; categorizar centenas de artigos publicados em periódicos pedagógicos sobre o ensino de matemática nos primeiros anos escolares e sobre a formação de professor; estudar os textos contidos numa gama enorme de cadernos escolares; fichar e organizar os textos de livros didáticos e manuais pedagógicos de centenas de obras; analisar as provas e exames de matemática de alunos e concursos de professores dentre outras tarefas requer expediente diferente das formas tradicionais de tratamento das fontes documentais de pesquisa. Tal desafio coloca noutros termos a pesquisa qualitativa e quantitativa.

\section{CONSIDERAÇÕES FINAIS}

Os estudos pertencentes ao campo Educação Matemática voltam-se para as ações a serem desenvolvidas no presente, ou em futuro próximo. Caracterizam-se, no mais das vezes, por prescrições em busca da melhoria do ensino e da aprendizagem da matemática na Escola Básica. Tal finalidade é perfeitamente legítima e encontra guarida tanto no âmbito acadêmico, quanto no senso comum pedagógico: é preciso que as pesquisas tenham algo a propor para que seja modificado o panorama sempre atual relativo aos problemas do baixo índice de aprendizagem da matemática na escola. Nesse sentido, a formação de professores que ensinam matemática revela-se como tema importante de pesquisas. 
Caberá formar melhor o professor de modo a que se possa ter um profissional que realize bem o seu ofício. As urgências do cotidiano impõem propostas de modificação no ensino e na formação de professores. A existência da tensão entre a demanda social - melhorar o ensino de matemática - e a pesquisa acadêmica — elaboração de problemáticas teóricas de modo a melhor compreender o fenômeno educativo do ensino da matemática e da formação de professores - parece constituir o motor da produção de novos saberes.

Analisando em retrospectiva os projetos encerrados e aqueles em andamento, que vêm mobilizando os pesquisadores do Grupo, nota-se que o traço comum no movimento das pesquisas, desde do início de suas atividades, liga-se ao interesse em investigar as transformações do saber. Em tempo primeiro, o saber posto em forma de disciplina escolar - a matemática do secundário; em seguida, com a proposta de análise da matemática do curso primário, tem-se o saber que é explicitado por meio das matérias escolares - a matemática dos primeiros anos escolares. Por último, com um foco voltado para a formação de professores, surgiu o interesse na pesquisa sobre os saberes profissionais, vistos como uma articulação entre aqueles do ensino e os da formação para a docência.

Os estudos inscritos no âmbito das Humanidades Digitais possibilitam por meio da tecnologia computacional com ferramental estatístico o diálogo entre o local e global, permitem que seja possível a caracterização, num dado tempo histórico, de referências para a formação de professores, por meio da transformação de milhares de informações em saber. Tais processos levam a tratar de modo diverso a pesquisa qualitativa. Esse é o grande desafio colocado atualmente para as investigações do GHEMAT Brasil.

\section{Nota sobre o autor}

WAGner Rodrigues Valente possui graduação em Engenharia (Escola Politécnica) pela Universidade de São Paulo (1979) e Pedagogia pela Universidade Santa Cecília dos Bandeirantes (1987), mestre em História e Filosofia da Educação pela Pontifícia Universidade Católica de São Paulo (1991) e doutor em Educação pela Universidade de São Paulo/ INRP- Paris (1997). Pós-Doutor pela Pontifícia Universidade Católica de 
São Paulo (1999). Livre Docente no Departamento de Educação da Universidade Federal de São Paulo (2010). Professor Associado da Universidade Federal de São Paulo. Editor da HISTEMAT - Revista de História da Educação Matemática. Na pesquisa investiga principalmente os seguintes temas: livro didático de matemática, didática da matemática, história da educação matemática e história da matemática.

\section{REFERÊNCIAS}

Burke, Peter. ¿Qué es la historia del conocimiento? Cómo la información dispersa se ha convertido en saber consolidado a lo largo de la historia. Argentina: Siglo Veintiuno Editores, 2017.

Café, Ligia, Miguel Ángel Márdero Arellano, Elza María Ferraz Barboza, Bianca Amaro de Melo y Eny Marcelino de Almeida Nunes. «Repositórios Institucionais: nova estratégia de publicação científica na rede». Anais. ENDOCOM, Belo Horizonte, MG 13 (set. 2003).

Clobridge, Abby. Building a Digital Repository Program with limited resources. Oxford: Chandos Publishing, 2010.

Costa, David A. e Wagner R. Valente (orgs.) Saberes matemáticos no curso primário: o que, como e por que ensinar?. São Paulo: LF Editora, 2014.

Mendes, Iran Abreu e Wagner R. Valente (orgs.). A Matemática dos manuais escolares: curso primário, 1890-1970. São Paulo: Editora Livraria da Física, 2017.

Ossenbach-Sauter, Gabriela. «Historia de las disciplinas y manualística escolar». En Educación, Historia y Sociedad - El legado historiográfico de Antonio Viñao, editado por Pedro Luis Moreno, 133-166. Valencia: Tirant Humanidades, 2018.

Pinto, Neuza B. e Wagner R. Valente (orgs.). Saberes elementares matemáticos em circulação no Brasil: dos documentos oficiais às revistas pedagógicas, 1890-1970. São Paulo: L F Editorial, 2016.

Viana, Cassandra L., Miguel Ángel Márdero Arellano e Milton Shintaku. «Repositórios institucionais em ciência e tecnologia: uma experiência de customização do DSpace». Instituto Brasileiro de Informação em Ciência e Tecnologia - IBITIC. Disponível em: http://bibliotecas-cruesp.usp.br/3sibd/docs/ viana358.pdf. 